Check for updates

Cite this: RSC Adv., 2019, 9, 32966

Received 5th July 2019

Accepted 8th October 2019

DOI: $10.1039 / c 9 r a 05097 c$

rsc.li/rsc-advances

\section{Heterogeneous Fenton-like activity of novel metallosalophen magnetic nanocomposites: significant anchoring group effect $\dagger$}

\author{
Narges Keikha, Abdolreza Rezaeifard (iD * and Maasoumeh Jafarpour (iD *
}

Two new pyridine and thiolate anchoring groups were prepared to functionalize $\gamma$ - $\mathrm{Fe}_{2} \mathrm{O}_{3}$ nanoparticles for coordinative attachment of simple Fe(III)- and $\mathrm{Mn}($ III)salophen complexes. Four new magnetically recoverable composites were characterized by several analytical techniques such as FT-IR, XRD, TGA, EDS compositional analysis and VSM to confirm superparamagnetic properties. TEM images revealed the nanostructure nature of composites with size ranging between 20 and $40 \mathrm{~nm}$. A heterogeneous advanced oxidation process for degradation of some organic dyes as water pollution compounds using an aqueous solution of $\mathrm{H}_{2} \mathrm{O}_{2}$ were successfully exploited. Several key parameters including the metal center in the salophen complex, initial $\mathrm{pH}$, catalyst dosage, $\mathrm{H}_{2} \mathrm{O}_{2}$ and dye concentration and temperature were investigated. A significant effect of the anchoring ligand on the degradation efficiency and catalyst stability was documented. The superior catalytic activity and particularly durability of the thiolate-based catalysts were demonstrated in comparison with their Py counterparts. Rate constants of $0.21,0.17,0.23$ and $0.11 \mathrm{~min}^{-1}$ were obtained for degradation of rhodamine $B(\mathrm{RhB})$, methylene blue $(\mathrm{MB})$, methyl orange (MO), and crystal violet (CV). Finally, a photoluminescence probing technology and radical scavenging measurements were carried out to elucidate the active species involved in the process.

\section{Introduction}

Many efforts have been devoted to developing technologies that are able to minimize the environmental impact of industrial waste. Numerous chemicals such as dyes are extensively employed to impart color to various industrial products. ${ }^{1}$ These dyes are the most problematic pollutants of textile wastewaters. This fact occurs because after the reactive dyeing process is finished, more than $15 \%$ of the textile dyes are lost in the wastewater stream during the dyeing operation. ${ }^{2}$ During the last decade, a series of new methods for water and wastewater purification have been developed. Advanced oxidation processes (AOPs) which revolve around the generation of strongly oxidizing hydroxyl free radicals $\left(\mathrm{OH}^{*}\right)$ that quickly and non-selectively oxidize a broad range of organic pollutants have received considerable attention. ${ }^{3} \mathrm{H}_{2} \mathrm{O}_{2}$ which produces water as the sole product has been extensively employed in environmentally benign oxidative degradation of organic pollutants via reactive oxygen species (ROS), such as $\mathrm{OH}^{\cdot}$ and $\mathrm{HO}_{2}{ }^{\circ} / \mathrm{O}_{2}{ }^{--}$after activation by catalysts. ${ }^{4}$

Catalysis Research Laboratory, Department of Chemistry, Faculty of Science, University of Birjand, Birjand, 97179-414 Iran. E-mail: rrezaeifard@birjand.ac.ir; mjafarpour@birjand.ac.ir; Fax: +98 56 32202515; Tel: +98 5632202516

$\dagger$ Electronic supplementary information (ESI) available. See DOI: 10.1039/c9ra05097c
An emerging field in AOPs is the application of magnetic nanoparticles (MNPs) as catalyst or support to offer easily and efficient isolation of catalyst after degradation of pollutants. ${ }^{5}$ The application of a magnetic field of low intensity induces the magnetization of the material and thus makes the use of a magnetic force possible, but when the magnetic field is cut off, the magnetization immediately decreases to zero. ${ }^{6}$ This last point is important for the release of particles after degradation of pollutants from aqueous media. Since, magnetite $\left(\mathrm{Fe}_{3} \mathrm{O}_{4}\right)$ nanoparticles are highly susceptible to be oxidized to maghemite $(\gamma$ $\mathrm{Fe}_{2} \mathrm{O}_{3}$ ) nanoparticles in the presence of oxygen, ${ }^{7}$ the chemical applications of maghemite are significantly on the rising. ${ }^{8}$ However, because of the high surface energy, the naked magnetic nanoparticles are generally unstable and aggregate easily, which strongly affects their dispersion into aqueous medium. To overcome such limitations, various surface modification methods have been developed to modify the surface of nanoparticles via loading of different organic, inorganic and biological materials to improve the dispersibility, stability, biocompatibility and biodegradability for specific purposes. ${ }^{9}$ Moreover, the functionalization and surface modification of $\gamma-\mathrm{Fe}_{2} \mathrm{O}_{3}$ could enhance its capability as a support for immobilization of metal complexes, which decreases the catalyst leaching during reactions. ${ }^{10}$

Due to the crucial axial function of the thiolate groups of cysteine residues in cytochrome P-450, peroxidase, catalase and histidine imidazole in hemoglobin, ${ }^{\mathbf{1 1}, \mathbf{1 2}}$ more attentions have been paid to use of bio-relevant compounds for anchoring the large 
metal complexes such as porphyrin and salen complexes as model compounds of heme molecules. ${ }^{13}$ The mobility of the catalyst and the solidity of the attachment to the support are further benefits to encourage the use of anchoring ligands in immobilization process. ${ }^{14}$ Recently, as a part of our research projects we attached porphyrin, phthalocyanine and salen complexes to functionalized silica magnetic nanoparticles (SMNP) for catalytic applications in aqueous oxidation of organic compounds. ${ }^{15,16}$ In this work, we have designed two new anchoring ligands using condensation of a new silica carbonyl compound with 4-aminopyridine (SAPy) and 2aminoethanethiol (SAET) to attach the Fe(III)- and Mn(III)salophenCl (FeSal, MnSal) complexes to SMNPs and provide an axial ligand for the metal center similar to the fifth iron-porphyrin ligand in heme-containing enzymes. ${ }^{11}$ The as-prepared magnetic nanocatalysts were employed successfully for dyes degradation using aqueous solution of $\mathrm{H}_{2} \mathrm{O}_{2}$ to imitate the peroxidase enzyme reaction. Our results revealed that $\mathrm{Fe}$ - and $\mathrm{Mn}$-complexes and $\mathrm{Fe}_{2} \mathrm{O}_{3}$ nanoparticles synergistically catalyzed dyes degradation offering a new perspective into the design of new catalyst to control the reaction by mediation of axial ligands and magnetic support together. A systematic investigation on the different parameters such as $\mathrm{pH}$, temperature, concentration of catalyst and oxidant and particularly nature of central metal and anchoring ligand on degradation of some dyes are presented. Bioinspired thiolatebased catalysts demonstrated higher catalytic activity and stability than those of Py counterparts. According to kinetic studies and scavenging experiments a possible mechanism is proposed.

\section{Experimental}

\subsection{Preparation of catalysts}

The procedures for the synthesis of $\gamma-\mathrm{Fe}_{2} \mathrm{O}_{3}$ (MNP), silica-coated maghemite nanoparticles (SMNP), Fe(III)salophenCl, and Mn(III) salophenCl complexes are given in ESI. $\dagger$ Herein, step by step procedures for preparation of catalysts are given as depicted in Schemes 1 and 2. Two new imine containing Si compounds
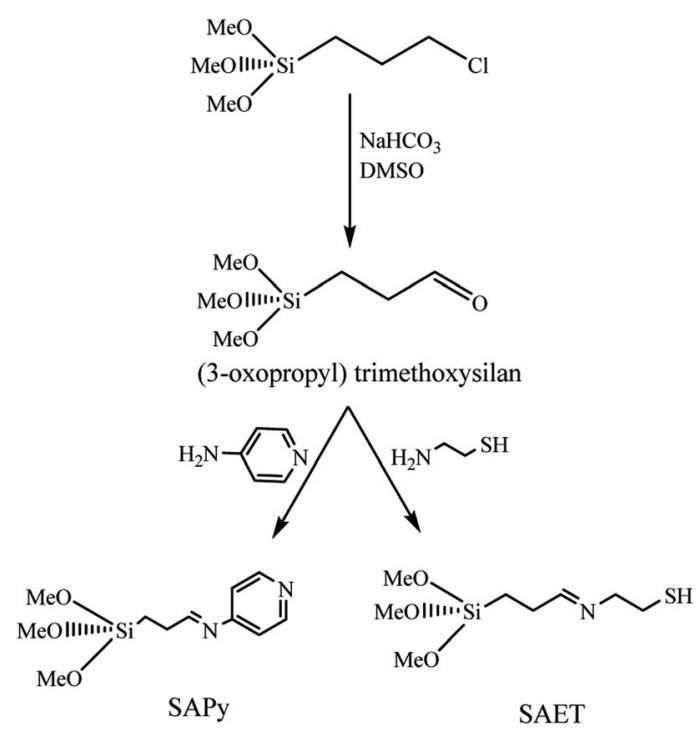

Scheme 1 Preparation of SAPy and SAET. have been prepared in this work as anchoring ligand for attachment of $\mathrm{Fe}(\mathrm{III})$ - and $\mathrm{Mn}$ (III)salophenCl to silica-coated maghemite nanoparticles (SMNP) (Scheme 1). For this purpose, (3-oxopropyl) trimethoxysilan prepared in our research group, ${ }^{17}$ was reacted with 4 -aminopyridine and 2 -aminoethanethiol producing two new imine compounds denoted here as SAPy and SAET, respectively.

\subsection{Preparation of SAPy}

The organosilicon aldehyde, (3-oxopropyl)trimethoxysilan, was synthesized according to method described in our previous report. ${ }^{17}$ For the synthesis of SAPy, to a solution of (3-oxopropyl) trimethoxysilan $(0.8 \mathrm{~mL}, 5 \mathrm{mmol})$ in ethanol $(10 \mathrm{~mL})$ was gradually added a solution of 4-aminopyridine $(0.470 \mathrm{~g}, 5$ $\mathrm{mmol})$ in ethanol $(10 \mathrm{~mL})$ at $60{ }^{\circ} \mathrm{C}$ under ultrasonic agitation and remained under the same conditions for $60 \mathrm{~min}$ (Scheme 1). The product precipitated after 24 hours at room temperature, which was filtered and washed with ethanol and dried in a vacuum desiccator (yield $85 \%$ ). The structure of product was characterized by FT-IR (Fig. S1 $\dagger$ ) and the composition and its purity were confirmed by elemental analysis. Cald: C, 51.94; $\mathrm{H}$, 7.13; N, 11.01; found: C, 52.82; H, 6.93; N, 10.87 .

\subsection{Preparation of SAET}

The SAET was prepared according to the same procedure used for preparation of SAPy, except for 4-aminopyridine which was replaced by 2-aminoethanethiol (0.385 g, $5 \mathrm{mmol}$ ) (Scheme 1).

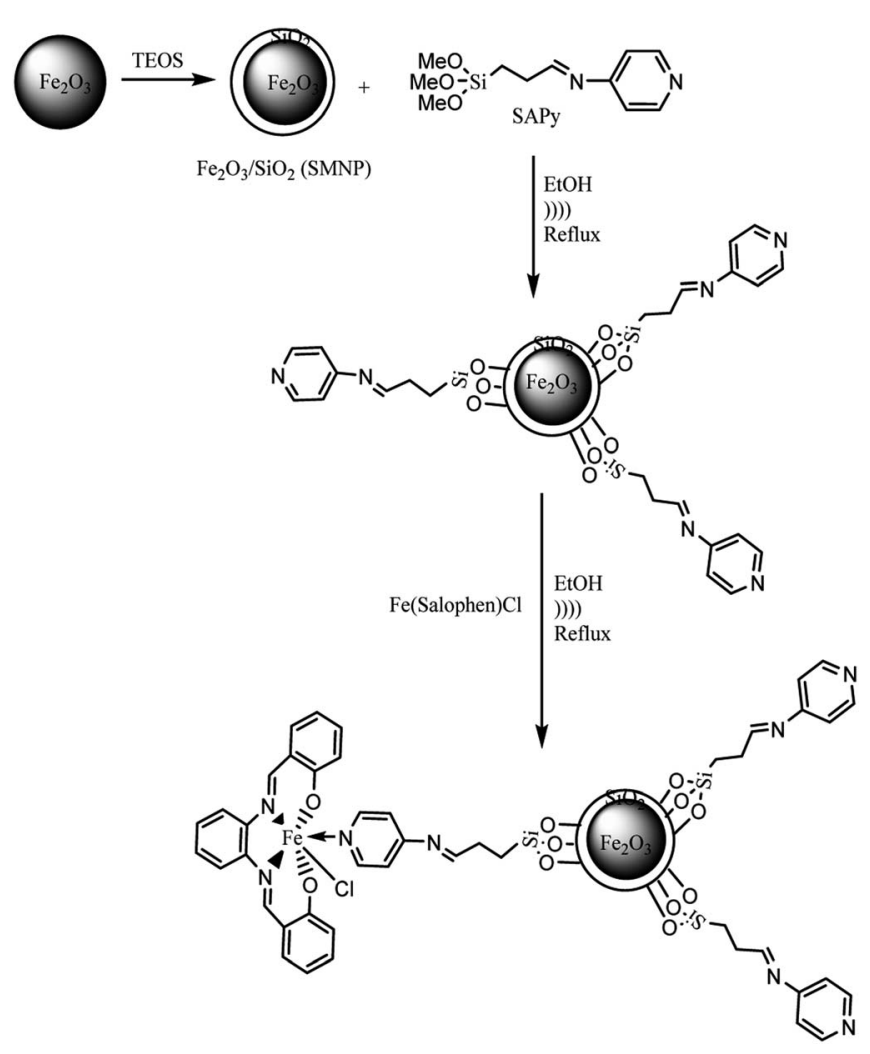

Scheme 2 Preparation of SMNP@SAPy/FeSal. 
The structure of product was characterized by FT-IR (Fig. S8 $\dagger$ ) and the composition and its purity were confirmed by elemental analysis. Cald: C, 40.48; H, 8.07; N, 5.90, found: 41.27; H, 7.89; N, 5.54.

\subsection{Preparation of SMNP@SAPy and SMNP@SAET}

$4.0 \mathrm{~g}$ of dry SMNP powder (see ESI $\dagger$ ) was mixed with $100 \mathrm{~mL}$ ethanol to produce a homogeneous suspension. Then $3.0 \mathrm{~g}$ of Schiff base ligands (SAPy or SAET) suspended in $50 \mathrm{~mL}$ ethanol was added dropwise to SMNP suspension, followed by sonication for $2 \mathrm{~h}$ at $60{ }^{\circ} \mathrm{C}$. Then the mixture was heated to $70{ }^{\circ} \mathrm{C}$ for $12 \mathrm{~h}$ while stirring (Scheme 2). The desired magnetic products were separated by an external magnetic field, sonicated in ethanol to remove unreacted Schiff base ligands and dried under vacuum.

\subsection{The attachment of $\mathrm{Fe}(\mathrm{III})$ salophenCl to SMNP@SAPy and SMNP@SAET}

To $1.0 \mathrm{~g}$ of SMNP@SAPy in $30 \mathrm{~mL}$ ethanol, was gradually added $0.5 \mathrm{~g}$ Fe(III)salophenCl $(2.0 \mathrm{mmol}$ ) (in a period of $10 \mathrm{~min}$ ) under ultrasonic agitation at $60^{\circ} \mathrm{C}$ followed by refluxing for $12 \mathrm{~h}$ (Scheme 2). The final sample was separated by an external magnetic field, washed with ethanol and dried under vacuum (Scheme 2). The same procedure was used for Mn(III)salophenCl complex.

\subsection{Procedure for catalytic dyes degradation}

In a typical process, $10 \mathrm{mg}$ SMNP@SAET/FeSal was added into $50 \mathrm{~mL}$ aqueous solution containing required concentration of $\mathrm{RhB}$ with $\mathrm{pH}=3.0$ under stirring, followed by addition of $62 \mu \mathrm{L}$ $\mathrm{H}_{2} \mathrm{O}_{2}$ solution (30\%). The $\mathrm{pH}$ was adjusted by the addition of appropriate amounts of $\mathrm{NaOH}$ or $\mathrm{HCl}$ solution. At given intervals, an appropriate amount of the suspension was taken out and filtered to remove the solid particles before analysis. The concentration of RhB was measured using spectrophotometer set at an absorbance maximum of $554 \mathrm{~nm}$. The decoloration ratio (DC) of RhB was calculated by eqn (1):

$$
\mathrm{DC}=\left(C_{0}-C_{\mathrm{t}}\right) / C_{0} \times 100
$$

Where $C_{0}\left(\mathrm{mg} \mathrm{L}^{-1}\right)$ and $C_{\mathrm{t}}\left(\mathrm{mg} \mathrm{L}^{-1}\right)$ are the initial and final $\mathrm{RhB}$ concentrations, respectively. This was used to evaluate the activity of catalyst.

\section{Results and discussion}

\subsection{Characterization of the SMNP@SAPy/FeSal}

The FT-IR spectrum of the SAPy Schiff base ligand is given in Fig. S1.† Peaks at 1027.8 and $1125.2 \mathrm{~cm}^{-1}$ are assigned to the stretching vibrations of the $\mathrm{Si}-\mathrm{O}$ bond at the SAPy structure. ${ }^{17}$ The band at $1659.4 \mathrm{~cm}^{-1}$ is characteristic of the $\mathrm{C}=\mathrm{N}$ bond featuring a strong evidence for the formation of Schiff base ligand. ${ }^{17}$ The peak at the $2950 \mathrm{~cm}^{-1}$ is attributed to the stretching vibrations of the aliphatic $\mathrm{C}-\mathrm{H}$ bonds of propyl. The broad band at the $3436.5 \mathrm{~cm}^{-1}$, is related to the $\mathrm{O}-\mathrm{H}$ stretching of the water in the structure. The comparative FT-IR spectra of MNP, SMNP, SMNP@SAPy and the SMNP@SAPy/FeSal is given in Fig. 1. The bands at 554.4 and $625.7 \mathrm{~cm}^{-1}$ substantiate the presence of the maghemite core (Fig. 1a). ${ }^{18}$ The broad peaks at about $900-1200 \mathrm{~cm}^{-1}$, assigned to the $\mathrm{Si}-\mathrm{O}-\mathrm{Si}$ and $\mathrm{Si}-\mathrm{OH}$ stretching vibrations, show the silica coating of maghemite nanoparticles (Fig. 1b). ${ }^{19,20}$ The bands at 3439 and $1629 \mathrm{~cm}^{-1}$ attributed to $\mathrm{O}-\mathrm{H}$ stretching and bending of adsorbed water molecules. ${ }^{20}$ The FT-IR spectra of SMNP@SAPy (Fig. 1c) show the $\mathrm{C}-\mathrm{H}$ stretching vibration bands of the SAPy group at $2952 \mathrm{~cm}^{-1} \cdot{ }^{21}$ The frequency of $\mathrm{C}=\mathrm{N}$ bond of SAPy Schiff base compound shifted slightly to $1660.4 \mathrm{~cm}^{-1}$ after attachment to maghemite nanoparticles. The sharp peaks at 1130 and $1027 \mathrm{~cm}^{-1}$ are related to Si-O in the structure (Fig. 1c). Immobilization of $\mathrm{Fe}(\mathrm{III})$ salophenCl on functionalized magnetic nanoparticles was demonstrated by the appearance of signals at about $800-750$ and $1610-1300 \mathrm{~cm}^{-1}$ (Fig. 1d) corresponding to the vibration modes of neat Fe(III)salophenCl (Fig. S2 $\dagger$ ). ${ }^{22}$ The $\mathrm{C}=\mathrm{N}$ stretch of $\mathrm{Fe}(\mathrm{III})$ salophenCl $\left(1603 \mathrm{~cm}^{-1}\right.$, Fig. S2 $\left.\dagger\right)$ shifted slightly to $1609 \mathrm{~cm}^{-1}$ after coordination to pyridine axial ligand of SAPy (Fig. 1d). The similar results for successful immobilization of $\mathrm{Mn}$ (III)salophen complex on magnetic nanoparticles (SMNP@SAPy/MnSal) can be extracted using FT-IR spectra given in SI (Fig. S3, $\dagger$ the peak at $1652.69 \mathrm{~cm}^{-1}$ is related to the $\mathrm{C}=\mathrm{N}$ frequency of imine bonds of $\mathrm{Mn}(\mathrm{III})$ salophenCl).

The incorporation of the Msalophen ( $\mathrm{M}=\mathrm{Fe}, \mathrm{Mn})$ complexes into the magnetic catalyst was confirmed by elemental composition determined by EDX (Fig. S4 $\uparrow$ ). The distinct peaks of iron and Mn were appeared clearly alongside carbon, nitrogen, oxygen and silicon in the EDX spectrum. Chlorine is a counter ion for Fe(III) and $\mathrm{Mn}$ (III)salophen complexes as evidenced by EDX spectra.

The XRD patterns of SAPy@SMNP and SMNP@SAPy/MSal (M $=\mathrm{Fe}, \mathrm{Mn}$ ) are given in ESI (Fig. S5). $\uparrow$ It can be seen clearly that the cubic crystalline structure of iron oxide remains intact after modification with silica, organic compounds as well as transition metal complexes. ${ }^{23,24}$

Transmission electron microscopy (TEM) analysis of SMNP@SAPy/FeSal (Fig. 2) revealed the spherical particles ranging in size between $20-40 \mathrm{~nm}$.

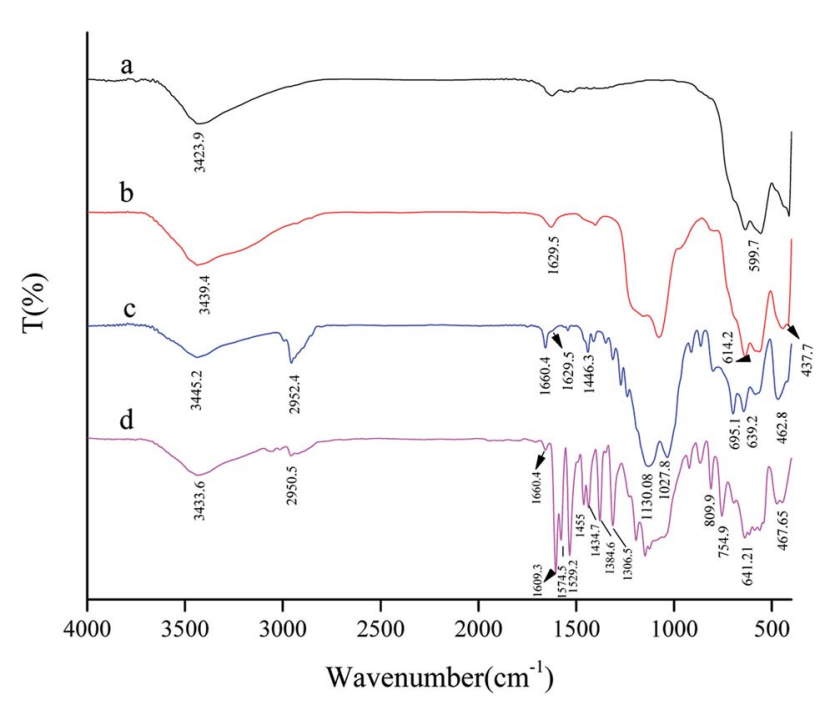

Fig. 1 FT-IR spectra of MNP (a), SMNP (b), SMNPASAPy (c) and SMNP@SAPy/FeSal (d). 
Thermal behavior of SMNP@SAPy/FeSal (Fig. 3B) demonstrated the stability of catalyst up to around $400{ }^{\circ} \mathrm{C}$ and after that the degradation of organic compounds including $\mathrm{Fe}(\mathrm{III})$ salophenCl occurred. ${ }^{\mathbf{1 6}} \mathrm{A}$ decrease in the weight percentage at about $150-250{ }^{\circ} \mathrm{C}$ related to desorption of water molecules from the catalyst surface. Decomposition of organic parts continued until $800{ }^{\circ} \mathrm{C}$. Comparative TGA thermograms of SMNP@SAPy (A) and SMNP@SAPy/FeSal (B) (Fig. 3), shows the same thermal behavior until $600{ }^{\circ} \mathrm{C}$. After that a weight loss of 12.4\% occurred for SMNP@SAPy/FeSal (Fig. 3B) which can be rationalized to incorporated Fe(III) salophenCl. According to this result, the amount of Fe supported on the surface of functionalized $\gamma-\mathrm{Fe}_{2} \mathrm{O}_{3}$ is $0.30 \mathrm{mmol} \mathrm{g}^{-1}$ close to result obtained by ICP-AES analysis $\left(0.33 \mathrm{mmol} \mathrm{g}^{-1}\right)$ obtained by difference in iron-containing SMNP@SAPy/FeSal and SMNP@SAPy. The TGA thermograms of SMNP@SAPy/MnSal is also given in ESI (Fig. S6) $\bullet \dagger$ The amount of $\mathrm{Mn}$ is estimated to be $0.30 \mathrm{mmol} \mathrm{g}^{-1}$ (0.28 $\mathrm{mmol} \mathrm{g}^{-1}$ according to ICP-AES analysis).

The magnetic properties of the as-synthesized $\gamma-\mathrm{Fe}_{2} \mathrm{O}_{3}$, SMNP@SAPy, SMNP@SAPy/FeSal and recycled nanocatalyst were measured using a magnetometer at $298 \mathrm{~K}$ (Fig. 4). The four materials exhibited a superparamagnetic behavior and no obvious remanence was recorded when the applied magnetic field was removed. The magnetization saturation (Ms) values of the assynthesized $\gamma-\mathrm{Fe}_{2} \mathrm{O}_{3}$, SMNP@SAPy, SMNP@SAPy/FeSal and recycling nanocatalyst were $61.42,43.35,18.72$, and $16.53 \mathrm{emu} \mathrm{g}^{-1}$, respectively. All synthesized materials shows exactly the same behavior of the $\gamma-\mathrm{Fe}_{2} \mathrm{O}_{3}$ magnetic nanoparticles albeit with less intensity owing to the organic coating on the surface of the magnetic nanoparticles that is the reason for the successful synthesis of the catalyst. Slight change in the magnetization saturation (Ms) value of the reused catalyst (Fig. 4D, $16.53 \mathrm{emu} \mathrm{g}^{-1}$ ) compared with fresh one (Fig. 4C, $18.72 \mathrm{emu} \mathrm{g}^{-1}$ ) affirms well that the catalyst preserved its integrity during the oxidation reaction. The magnetic properties of Mn(III)salophenCl attached to SMNP@SAPy is given in ESI (Fig. S7).†

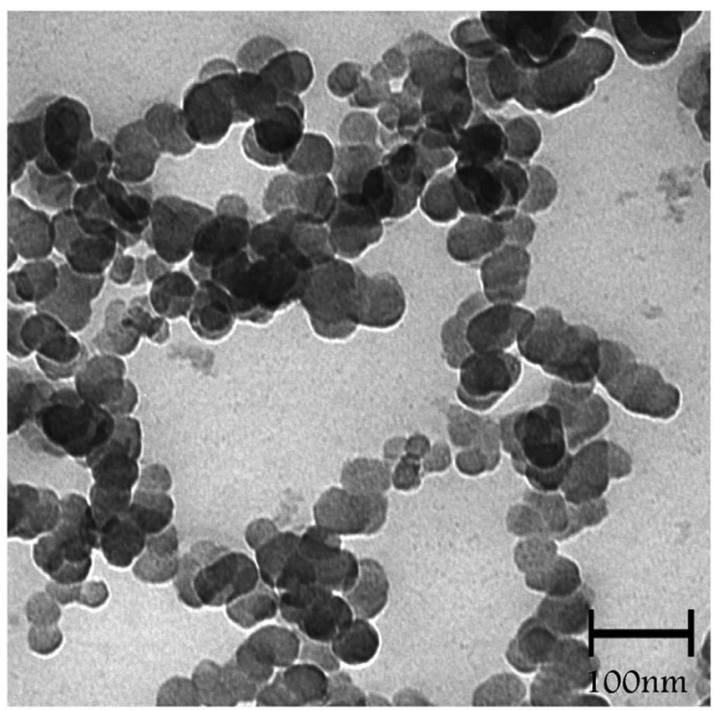

Fig. 2 TEM image of SMNP@SAPy/FeSal nanocatalyst.

\subsection{Synthesis and characterization of bio-inspired SMNP@SAET/Metallosalophen}

To investigate the effect of anchoring group, 4-aminopyridine was replaced by 2-aminoethanthiol to react with (3-oxopropyl) trimethoxysilan, ${ }^{17}$ producing a new imine compound containing a thiolate group denoted as SAET (Scheme 1). Thiolate ligands are of extreme interest in coordination chemistry, ${ }^{25}$ because of key function of thiolate groups of cysteine residues in iron and zinc enzymes. $^{26}$ They have also found important applications in the fields of nanoscience. ${ }^{27}$ By imitating of the peroxidase enzyme structure, coordinative attachment of Fe(III)salophenCl to SAETfunctionalized SMNP through thiolate group gave SMNP@SAET/FeSal as a bio-inspired magnetically recoverable composite. The results for characterization of SAET, SMNP@SAET and SMNP@SAET/MSal $(\mathbf{M}=\mathrm{Fe}, \mathrm{Mn})$ are given in ESI (FT-IR, EDX, XRD, TGA, Fig. S8-S13).† According to FT-IR spectra, the $\mathrm{C}=\mathrm{N}$ frequency of the anchored ligand SAET at $1595.8 \mathrm{~cm}^{-1}$ shifted to $1601.59 \mathrm{~cm}^{-1}$ after coating the SMNP (Fig. S9a and $\left.\mathrm{b}^{\dagger}\right)$. The incorporation of MsalophenCl $(\mathrm{M}=\mathrm{Fe}$, $\mathrm{Mn}$ ) into functionalized magnetic nanoparticles were evidenced by the appearance of new signals in FT-IR spectra depicted in Fig. S9c and d. $\dagger^{22}$ More evidence was obtained by EDX compositional analysis. Fig. S11† illustrates the distinct peaks of carbon, chlorine, nitrogen, oxygen, silica, sulfur, Fe and Mn in the EDX spectrum that confirmed the successful incorporation of the both complexes on the surface of the magnetic nanoparticles. The amounts of $\mathrm{Fe}$ and Mn loaded on SAET-functionalized SMNP were found to be 0.13 and $0.06 \mathrm{mmol} \mathrm{g}^{-1}$, respectively.

\subsection{Degradation performance of SMNP@SAET/FeSal}

3.3.1 Preliminary tests for RhB degradation. Knowing that $\mathrm{H}_{2} \mathrm{O}_{2}$ solution is not able to decompose RhB (Fig. 5), ${ }^{24,28}$ the reaction mixture subjected to catalytic amount of the assynthesized SMNP@SAET/FeSal composite compared with parent materials at the same conditions (Fig. 6). The results presented in Fig. 6, clearly confirmed the superior catalytic activity of title magnetically recoverable salophen catalyst.

The influences of $\mathrm{pH}$, catalyst dosage and $\mathrm{H}_{2} \mathrm{O}_{2}$ concentration on RhB degradation in the presence of SMNP@SAET/FeSal were confirmed. As shown in Table 1, an acidic solution with a $\mathrm{pH}$ of 3.0 seems more favorable for degradation activity of catalyst to remove $\mathrm{RhB}$ completely after $70 \mathrm{~min}$ at $25{ }^{\circ} \mathrm{C}$. The faster formation of $\mathrm{Fe}(\mathrm{II})$ at acidic media may be a good reason for such an exhibition considering this fact that, the classic Fenton reaction occurs in the presence of $\mathrm{Fe}(\mathrm{II})$ to produce hydroxyl radical from $\mathrm{H}_{2} \mathrm{O}_{2}$ (eqn. 2). Thus, the catalytic efficiency of $\mathrm{Fe}(\mathrm{III})$-containing complexes such as peroxidase and the related bioinspired compounds like those synthesized in this work, largely depends upon the rate of $\mathrm{Fe}^{\mathrm{III}}$ to $\mathrm{Fe}^{\mathrm{II}}$ transformation (eqn. 3). ${ }^{\mathbf{2 9}, 30}$ However, the stability of the Fe(III)salophen complex in the acidic $\mathrm{pH},{ }^{29}$ should be taken into account.

$$
\begin{gathered}
\mathrm{Fe}^{2+}+\mathrm{H}_{2} \mathrm{O}_{2}+\mathrm{H}^{+} \rightarrow \mathrm{Fe}^{3+}+\cdot \mathrm{OH}+\mathrm{H}_{2} \mathrm{O} \\
\mathrm{Fe}^{3+}+\mathrm{H}_{2} \mathrm{O}_{2} \rightarrow \mathrm{Fe}^{2+}+\cdot \mathrm{OOH}+\mathrm{H}^{+}
\end{gathered}
$$




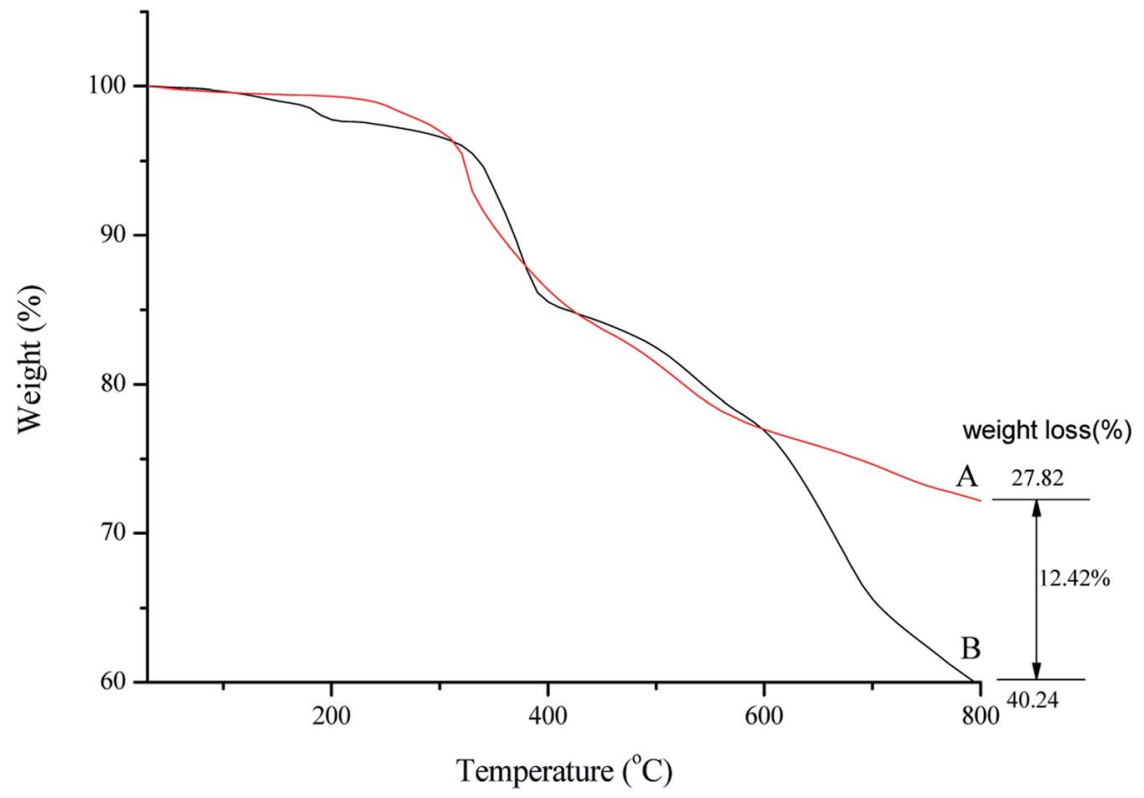

Fig. 3 TGA thermograms of SMNP@SAPy (A) and SMNP@SAPy/FeSal (B).

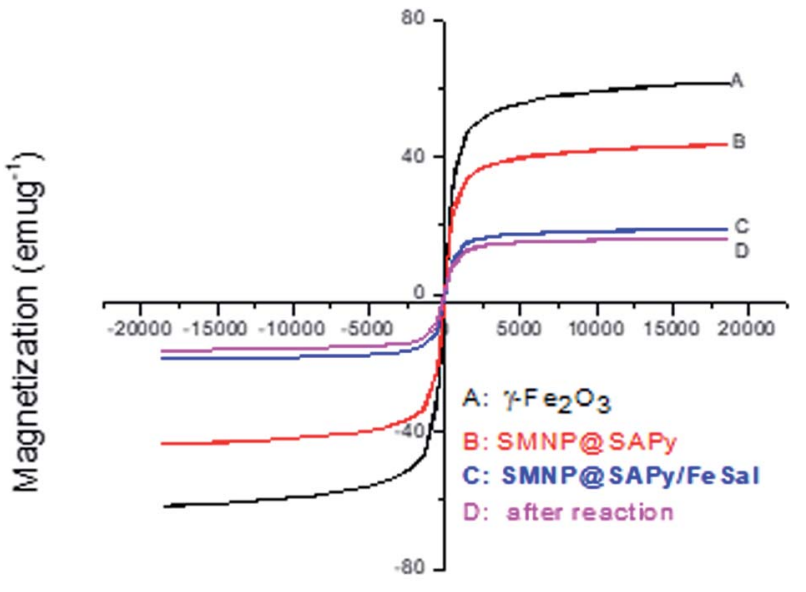

Field(G)

Fig. 4 Magnetic hysteresis curves of the pristine $\gamma-\mathrm{Fe}_{2} \mathrm{O}_{3}$ (A), SMNP@SAPy (B), SMNP@SAPy/FeSal (C) and recycled nanocatalyst (D) at $298 \mathrm{~K}$.

The effect of the initial pollutant concentration was also investigated. According to the results presented in Table 2, the method is efficiently applicable for a solution of 2 to $20 \mathrm{ppm}$<smiles>CCN(CC)c1ccc2c(-c3ccccc3C(=O)O)c3ccc(=[N+](CC)CC)cc-3oc2c1</smiles>

Fig. 5 Molecular Structure of the RhB.
RhB within 70-280 min using $62 \mu \mathrm{L} \mathrm{H}_{2} \mathrm{O}_{2}$ and $10 \mathrm{mg}$ of solid catalyst (0.026 mmol Fesalophen complex). Degradation rate was dependent to catalyst loading and reduced when the lower catalyst was used. For example, removal of $2 \mathrm{ppm}$ RhB took 70 and $210 \mathrm{~min}$ using 10 and $5 \mathrm{mg}$ catalyst. Moreover, for $50 \mathrm{ppm}$ $\mathrm{RhB}$, using $1.5 \mathrm{~mL} \mathrm{H}_{2} \mathrm{O}_{2}$ and 10 and $20 \mathrm{mg}$ catalyst, 23.5 and $40 \%$ removal efficiency were observed within 280 min respectively, indicating that the method is amenable for scale up procedure.

\subsection{Effect of reaction temperature}

The time course of RhB degradation in SMNP@SAET/FeSal/ $\mathrm{H}_{2} \mathrm{O}_{2}$ system at different temperature $\left(35-50{ }^{\circ} \mathrm{C}\right)$ is depicted in Fig. 7. The degradation of RhB significantly accelerated by

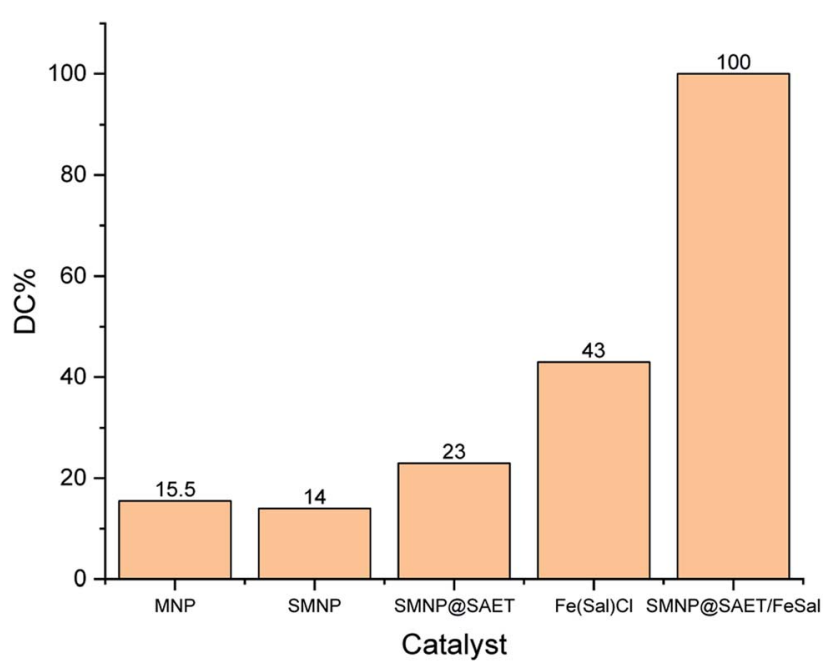

Fig. 6 Comparing of catalytic activity of SMNPQSAET/FeSal with parent materials. The aqueous solution with a $\mathrm{pH}$ of 3.0 containing $2 \mathrm{ppm} \mathrm{RhB}$ and $62 \mu \mathrm{L} \mathrm{H}_{2} \mathrm{O}_{2}$ and $2 \mathrm{mmol}$ catalyst were run under air for 70 min. 
Table 1 The effect of $\mathrm{pH}$ on RhB removal efficiency of SMNP@SAPy/ FeSal. $^{a}$

\begin{tabular}{ll}
\hline $\mathrm{pH}$ & DC (\%) \\
\hline 2 & 95 \\
3 & 100 \\
4 & 90 \\
5 & 89 \\
6 & 45 \\
7 & 38 \\
8 & 29 \\
9 & 15
\end{tabular}

${ }^{a}$ The reaction were run under air for $70 \mathrm{~min}$ at $25{ }^{\circ} \mathrm{C}$ using $10 \mathrm{mg}$ catalyst and $62 \mu \mathrm{L} \mathrm{H}_{2} \mathrm{O}_{2}$.

rising the temperature and a lag time observed in the degradation reaction at lower temperatures could be rationalized to retarded transformation of $\mathrm{Fe}^{\mathrm{III}}$ to $\mathrm{Fe}^{\mathrm{II}}$ (eqn 2), ${ }^{30}$ and consequently slow formation of active species. When the solution was heated from 25 to $50{ }^{\circ} \mathrm{C}$, the reaction accelerated 100 -fold and the reaction time decreased from 210 to $20 \mathrm{~min}$ for a solution of 5 ppm RhB (pseudo-first-order rate constant increased from 0.0016 to $0.2 \mathrm{~min}^{-1}$, Fig $\left.\mathrm{S} 14 \dagger\right)$. It could be caused by facile formation of active oxidants such as radical $\mathrm{OH}^{*},{ }^{31}$ or high valent $\mathrm{Fe}=\mathrm{O}$ species, ${ }^{32}$ under thermal activation. Nevertheless, further heating dropped the removal efficiency to 81 and $74 \%$ at 60 and $70{ }^{\circ} \mathrm{C}$ resulting from $\mathrm{H}_{2} \mathrm{O}_{2}$ destruction at high temperatures. ${ }^{33}$ We also evaluated title catalytic systems for oxidative degradation of other organic dyes such as methylene blue (MB), methyl orange (MO), and crystal violet (CV). According to results presented in Fig. 8 and Table 3, all pollutants can also be decomposed thoroughly and effectively within 25 min using Fe containing catalyst at the same condition used for RhB. The pseudo-first-order rate constant of dyes degradation (Table 3 and Fig. S15 $\dagger$ ) revealed that the complete degradations of dyes in this work occurred in a rapid manner. For example, the $k / \mathrm{min}$ for degradation of RhB in title system are 0.087 and $0.21 \mathrm{~min}^{-1}$ at 40 and $50{ }^{\circ} \mathrm{C}$, respectively, which are much larger than those reported for magnetic nanoparticle containing systems at different temperatures (6-200 fold). ${ }^{24,34}$ They are also consistent with those reported for photodegradation of organic dyes in the presence of $\mathrm{Fe}(\mathrm{III})$-complex $/ \mathrm{H}_{2} \mathrm{O}_{2}$ under visible light irradiation $\left(k=0.17\right.$ and $0.084 \mathrm{~min}^{-1}$ for $\mathrm{RhB}$ and $\mathrm{CV}$, respectively). ${ }^{29}$

\subsection{The effect of anchoring ligand and salophen metal center}

When SAET containing strong $\pi$-donor $-\mathrm{SH}$ group (Scheme 1 ) was replaced by SAPy having weak $\pi$-donor Py (Scheme 1), the catalytic degradation performance of magnetically recoverable catalyst decreased to less than half $(46.5 \%)$ under the same conditions (Table 4, entry 1 and 2). This result clearly shows that how a ferric site surrounded by thiolate ligand, ${ }^{35}$ surpass the corresponding catalysts containing Py. ${ }^{36}$ However, the activity of Mn-complex attached to thiolate ligand was 4 times lower than iron counterpart (26, entry 3) while, the corresponding Py axial ligand (SAPy) promoted partially its efficiency compared to iron catalyst (56 vs. 46 entries 2 and 4) (see ESI $\uparrow$ for characterization of SMNP@SAPy/MnSal, SMNP@SAET/MnSal). The higher catalytic activity of iron containing catalyst than that of Mn counterpart may be rationalized to Fenton mechanism mediated by iron center (eqn. 2). However, when $\mathrm{H}_{2} \mathrm{O}_{2}$ was replaced by more active $\mathrm{Na}_{2} \mathrm{~S}_{2} \mathrm{O}_{8}$ (Table 4 , entries $5-8$ ), both $\mathrm{Fe}$ and $\mathrm{Mn}$ sites surrounded by thiolate ligand SAET showed superior activity (100 and 82\% respectively) than those containing SAPy (46 and $48 \%$ respectively). Further and more important advantage of using SAET observed in this work is excellent durability of catalyst. The inspection of FT-IR spectra of used iron catalysts revealed some changes in vibration bands of SMNP@SAPy/ FeSal after reaction, while the spectra of thiolate containing counterpart, remained quite unchanged (Fig. 9). These results clearly demonstrate that anchoring ligand structure and coordinated atom help to change the ligand environment of central metal and then enhance catalytic efficiency and stability.

The electron $\pi$-donating ability and "push" capability of the $\mathrm{S}$ atom in thiolate group is stronger than the $\mathrm{N}$ atom in Pys and amines, ${ }^{37}$ making a metal center to be more appropriate for oxidation reactions results in the easier production of active oxidant such as $\mathrm{OH}^{-}$radicals. These advantages make the catalyst more active and persistent against the oxidative degradation. Moreover, the lone pair of $\mathrm{S}$ atom is prone to form hydrogen bonding with $\mathrm{H}_{2} \mathrm{O}_{2}$ adjacent to catalytic site which facilitates bond cleavage of peroxide. ${ }^{38}$ Thus, Fe(III)salophenCl anchored on thiolate-functionalized SMNP is an effective catalyst for removal of different structurally dyes pollutants, with further advantage of high catalyst durability.

\subsection{Radical quenching studies and possible degradation mechanism}

In order to identify the reactive oxygen species formed in the SMNP@SAET/FeSal catalyst $/ \mathrm{H}_{2} \mathrm{O}_{2}$-system, the photoluminescence probing technology and radical scavenging measurements were conducted. Disodium salt of the terephthalic acid (NaTA) could react with $\mathrm{OH}^{\bullet}$ to furnish 2-hydroxy terephthalic acid (HTA), which relies on the PL signal at $425 \mathrm{~nm}$.

Table 2 The screening of $\mathrm{RhB}, \mathrm{H}_{2} \mathrm{O}_{2}$ and catalyst concentration ${ }^{a}$

\begin{tabular}{lllll}
\hline & \multicolumn{2}{l}{ Time (min) } & & \\
\cline { 2 - 5 } $\mathrm{RhB}(\mathrm{ppm})$ & 70 & 140 & 210 & 280 \\
\hline 2 & $100^{b}$ & - & - & - \\
$2^{c}$ & 19 & 88 & 100 & \\
5 & 17 & 93 & 95 & - \\
10 & 9 & 46 & 79 & 87 \\
20 & 0 & 8 & 44 & 74.5 \\
$50^{d}$ & 5 & 16 & 18 & 23.5 \\
$50^{e}$ & 8 & 22 & 32 & 40
\end{tabular}

${ }^{a}$ The reaction were run in a solution of pH 3.0 under air at $25^{\circ} \mathrm{C}$ using $62 \mu \mathrm{L} \mathrm{H}_{2} \mathrm{O}_{2}$ and $10 \mathrm{mg}$ SMNP@SAET/FeSal catalyst. ${ }^{b} 6,32,81$ and $93 \%$ at $30,40,50$, and $60 \mathrm{~min}$ respectively. ${ }^{c} 5 \mathrm{mg}$ catalyst. ${ }^{d} 1.5 \mathrm{~mL} \mathrm{H}_{2} \mathrm{O}_{2}$. ${ }^{e} 1.5 \mathrm{~mL} \mathrm{H}_{2} \mathrm{O}_{2}$ and $20 \mathrm{mg}$ catalyst. 


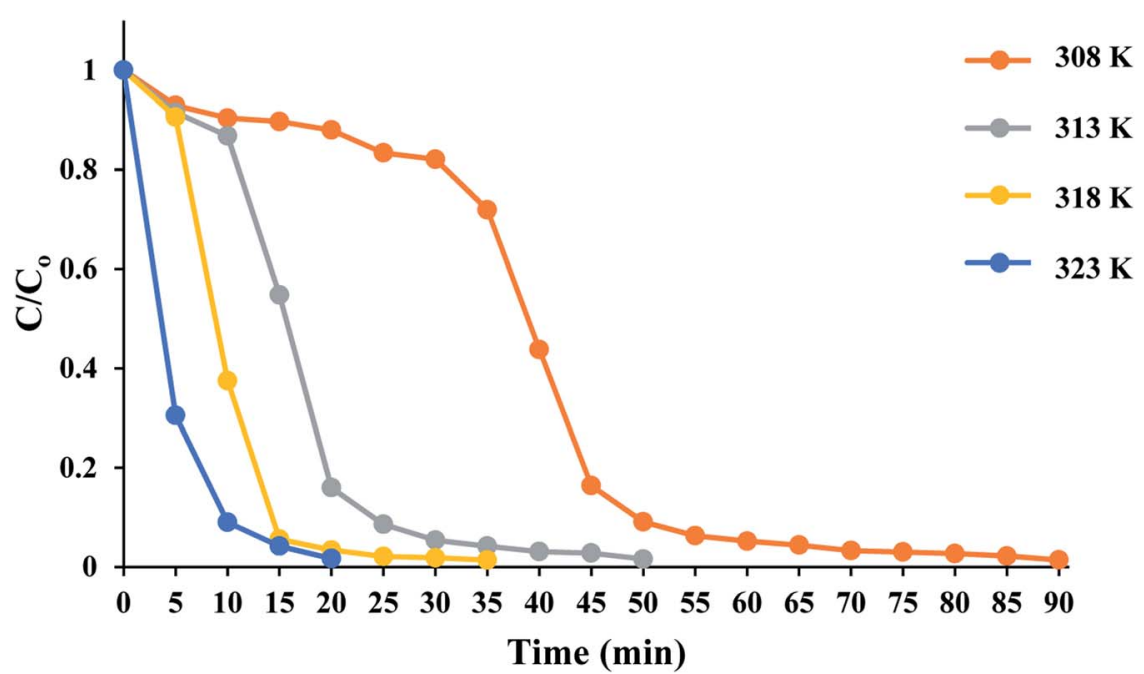

Fig. 7 Time course of RhB degradation at different temperatures. The reactions containing RhB (50 mL 5 ppm), $10 \mathrm{mg}$ SMNP@SAET/FeSal catalyst, and $62 \mu \mathrm{L} \mathrm{H} \mathrm{H}_{2} \mathrm{O}_{2}$ were run under air.

This reaction is unaffected by the presence of other reactive species such as $\mathrm{H}_{2} \mathrm{O}_{2}, \mathrm{HO}_{2}{ }^{\cdot}$ and $\mathrm{O}_{2}{ }^{-}$, so it could be used as a sensitive probe in detecting $\mathrm{OH}^{*}$ radicals. ${ }^{39}$ Fig. 10 shows the fluorescence spectra of the solution containing the SMNP@SAET/FeSal $/ \mathrm{H}_{2} \mathrm{O}_{2}$ system and NaTA. The control experiments confirmed that there is no NaTA fluorescence peak without the $\mathrm{H}_{2} \mathrm{O}_{2}$ (Fig. 10a). It can be seen that the fluorescence intensity increases sharply within $10 \mathrm{~min}$, implying that $\mathrm{OH}$ radicals were indeed generated in the system. Also, when we have used isopropanol as an effective hydroxyl radical scavenger, the degradation rate of dye gets reduced to $45 \%$ in the presence of the catalyst and $\mathrm{H}_{2} \mathrm{O}_{2}$ providing a strong evidence for involvement of hydroxyl radicals in degradation process. ${ }^{40}$ According to these experiments, $\mathrm{Fe}$ (III) is reduced to $\mathrm{Fe}(\mathrm{II})$ in the presence of $\mathrm{H}_{2} \mathrm{O}_{2}$ followed by reaction with $\mathrm{H}_{2} \mathrm{O}_{2}$ to produce
Fe(III) and hydroxyl radicals i.e. a classic Fenton reaction. Nevertheless, an excess amount of the isopropanol (124 mM) didn't stop the degradation process completely and DC percentage reached down ultimately to $36 \%$ indicating the involvement of secondary oxidant in this reaction. The contribution of $\mathrm{O}_{2}{ }^{-}$to the degradation of $\mathrm{RhB}$ was confirmed by addition of $p$-benzoquinone leading to a $40 \%$ decrease in decoloration rate. ${ }^{40}$ The involvement of oxo species $\mathrm{Fe}(\mathrm{v})$ or $\mathrm{Fe}(\mathrm{Iv})$ cation radical as well-known active species in peroxidaselike catalysis mediated by salen and porphyrin metal complexes in the presence of $\mathrm{H}_{2} \mathrm{O}_{2}$ may be a suggestion. ${ }^{29,32}$ Delayed reactions at lower temperatures in this work (Fig. 7) is related to formation of less reactive $\mathrm{Fe}^{\mathrm{III}}-\mathrm{OOH}$ species. At higher temperature, the formation of the active high-valent iron oxo species is favored ${ }^{32}$ and accordingly degradation of RhB was

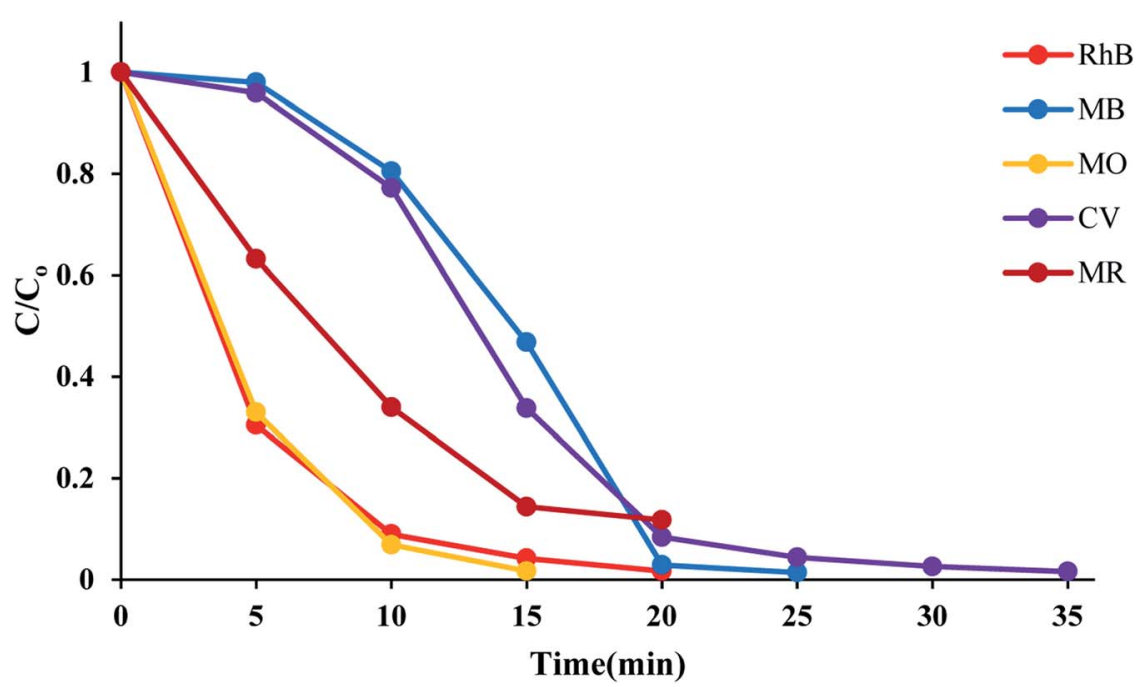

Fig. 8 Time course of dyes degradation at $50{ }^{\circ} \mathrm{C}$. The reactions containing $50 \mathrm{~mL}, 5 \mathrm{ppm}$ dye solution, $10 \mathrm{mg}$ SMNP@SAET/FeSal catalyst, $62 \mu \mathrm{L}$ $\mathrm{H}_{2} \mathrm{O}_{2}$ were run under air. 
Table 3 The pseudo-first-order rate constants of dyes degradation in SMNPaSAET/FeSal/ $\mathrm{H}_{2} \mathrm{O}_{2}$ system $^{a}$

\begin{tabular}{llll}
\hline Dye & $T\left({ }^{\circ} \mathrm{C}\right)$ & Time $(\min )$ & $k \min ^{-1}$ \\
\hline RhB & 25 & 210 & 0.0016 \\
RhB & 35 & 90 & 0.014 \\
RhB & 40 & 50 & 0.087 \\
RhB & 50 & 20 & 0.21 \\
MB & 50 & 20 & 0.17 \\
MO & 50 & 15 & 0.23 \\
CV & 50 & 25 & 0.11
\end{tabular}

${ }^{a} 50 \mathrm{~mL}$ solution with $\mathrm{pH}$ of 3.0 containing $5 \mathrm{ppm}$ dye, $10 \mathrm{mg}$ SMNP@SAET/FeSal catalyst, $62 \mu \mathrm{L} \mathrm{H}_{2} \mathrm{O}_{2}$ were run under air.

Table 4 The effect of anchoring group and metal center of $M(I I I)$ salophenCl ${ }^{a}$

\begin{tabular}{llll}
\hline Entry & SMNP catalyst & Oxidant & DC (\%) \\
\hline 1 & @SAET/FeSal & $\mathrm{H}_{2} \mathrm{O}_{2}$ & 100 \\
2 & @SAPy/FeSal & $\mathrm{H}_{2} \mathrm{O}_{2}$ & 46.5 \\
3 & @SAET/MnSal & $\mathrm{H}_{2} \mathrm{O}_{2}$ & 26 \\
4 & @SAPy/MnSal & $\mathrm{H}_{2} \mathrm{O}_{2}$ & 56 \\
$5^{b}$ & @SAET/FeSal & $\mathrm{Na}_{2} \mathrm{~S}_{2} \mathrm{O}_{8}$ & 100 \\
$6^{b}$ & @SAPy/FeSal & $\mathrm{Na}_{2} \mathrm{~S}_{2} \mathrm{O}_{8}$ & 46 \\
$7^{b}$ & @SAET/MnSal & $\mathrm{Na}_{2} \mathrm{~S}_{2} \mathrm{O}_{8}$ & 82 \\
$8^{b}$ & @SAPy/MnSal & $\mathrm{Na}_{2} \mathrm{~S}_{2} \mathrm{O}_{8}$ & 48
\end{tabular}

${ }^{a}$ The $50 \mathrm{~mL}$ solution of $2 \mathrm{ppm} \mathrm{RhB}$ at $\mathrm{pH}=3.0$ were run under air for 70 min using $2 \mathrm{mmol}$ catalyst (based on metal center content of MsalophenCl) attached to nanocomposites, $62 \mu \mathrm{L} \quad \mathrm{H}_{2} \mathrm{O}_{2} .{ }^{b}$ The reaction were run using $0.62 \mathrm{mmol}(147 \mathrm{mg}) \mathrm{Na}_{2} \mathrm{~S}_{2} \mathrm{O}_{8}$ at the same conditions used for $\mathrm{H}_{2} \mathrm{O}_{2}$.

triggered from the beginning at $50{ }^{\circ} \mathrm{C}$. The trace of GC-MS analysis of intermediates formed during degradation of $\mathrm{RhB}$ are shown in Fig. S16. $\dagger$ The lack of any peak with molecular mass of 433 confirmed quite removal of RhB. Moreover, no

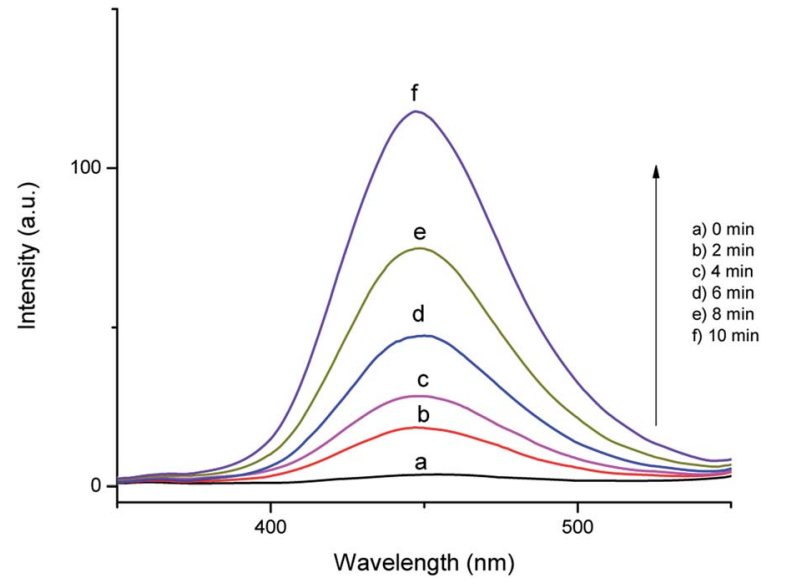

Fig. 10 The time course of photoluminescence spectra of the RhB solution at $\mathrm{pH} 3.0$ containing $10 \mathrm{mg}$ SMNP@SAET/FeSal catalyst, $10 \mathrm{mM} \mathrm{NaTA}$, and $12.0 \mathrm{mM} \mathrm{H}_{2} \mathrm{O}_{2}$ at $50{ }^{\circ} \mathrm{C}$.

evidences for $\mathrm{N}$-de-ethylated intermediates from $\mathrm{RhB}$ degradation were observed (molecular mass of 415, 387, 359, and 331 for one, di, tri and fully N-de-ethylated RhB products, respectively). More evidence was obtained by UV-vis spectral change of RhB during degradation (Fig. S17†). The characteristic absorbance peak of RhB at $554 \mathrm{~nm}$ gradually decreased without any peak shift, ruling out any N-deethylation of $\operatorname{RhB}(\lambda=498 \mathrm{~nm}) .{ }^{41}$ Thus, SMNP@SAET/FeSal is efficient enough to degrade the chromophore of the dye (RhB) successfully. ${ }^{42}$

\subsection{Recycling of the catalyst}

To verify the heterogeneous nature of catalysis in this work, hot filtration tests were performed. A control reaction was carried out in the presence of SMNP@SAET/FeSal solid catalyst. When the degradation rate of $\mathrm{RhB}$ reached to $15 \%$ at $10 \mathrm{~min}$, the solid was removed at the reaction temperature and the filtrate allowed to stir under the reaction temperature. As depicted in Fig. 11A, no further noticeable degradation was occurred. This
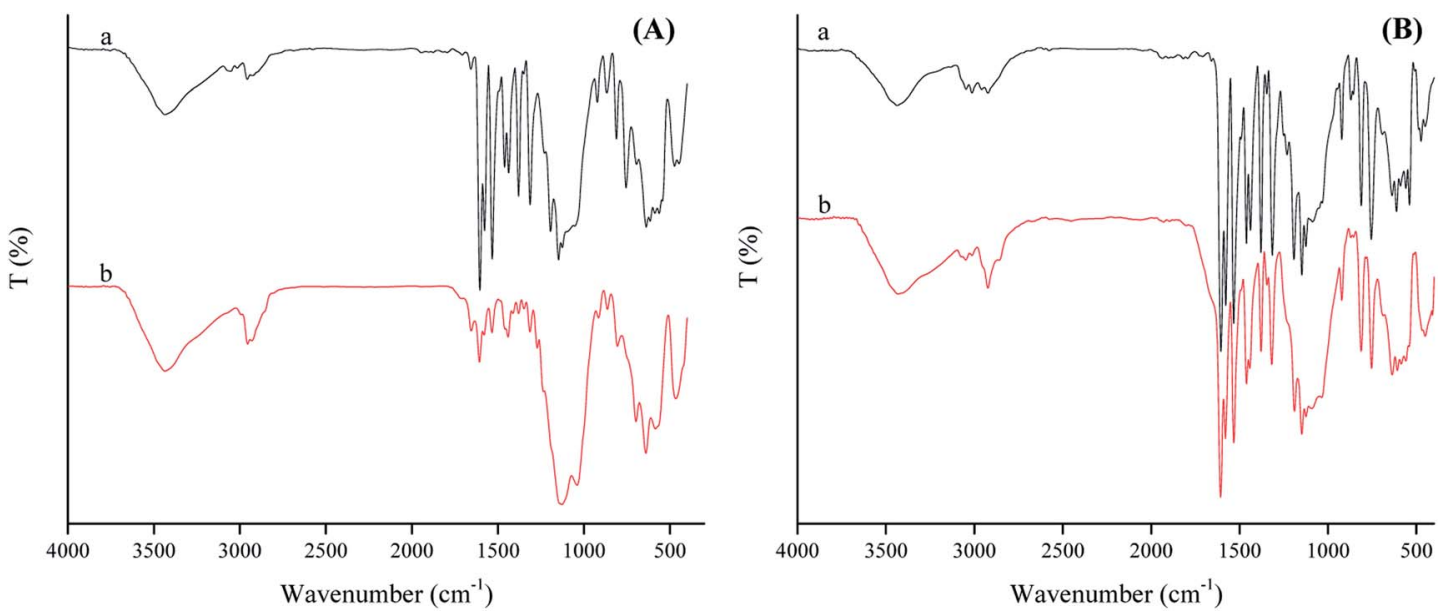

Fig. 9 FT-IR spectrum represents fresh (a) and reused (b) spectrum of SMNPaSAPy/FeSal (A) and SMNPaSAET/FeSal (B) from RhB degradation reaction using $\mathrm{H}_{2} \mathrm{O}_{2}$. 

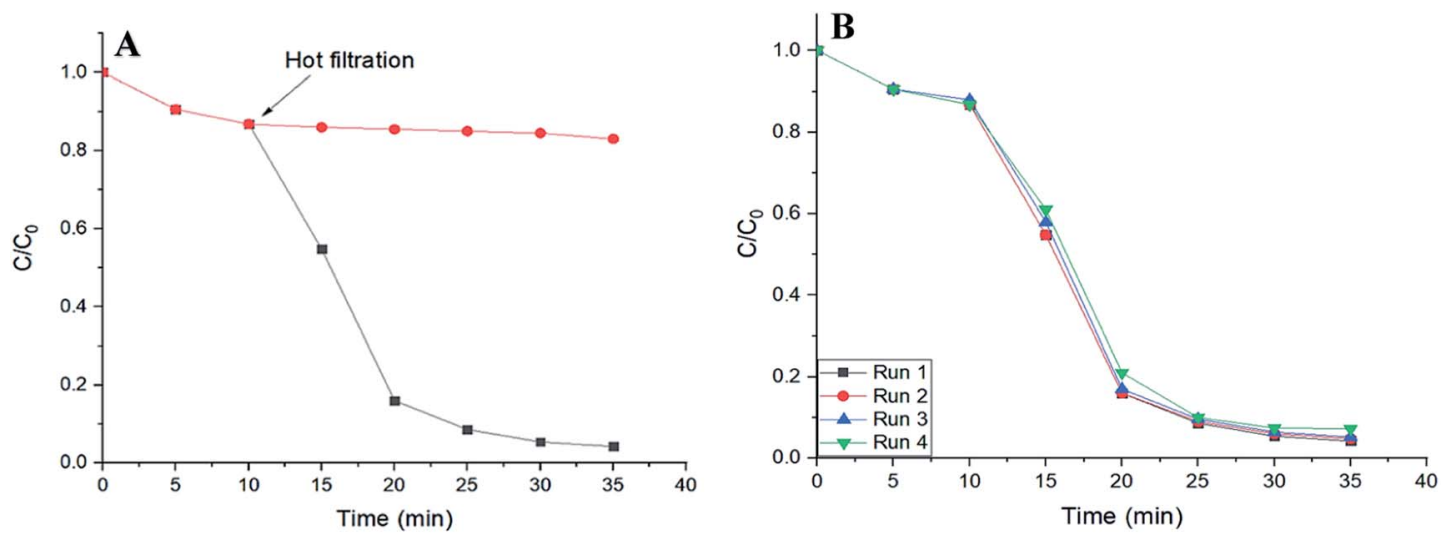

Fig. 11 (A) Time plot for degradation of $50 \mathrm{~mL} \mathrm{RhB}$ solution (2 ppm) using $62 \mu \mathrm{L} \mathrm{H}_{2} \mathrm{O}_{2}$ in the presence of SMNP@SAET/FeSal at $40{ }^{\circ} \mathrm{C}$. (B) Four runs recovery of SMNP@SAET/FeSal catalyst for the degradation of RhB under the same conditions.

indicates that no active species was present in the supernatant. ICP analysis of the filtrate showed trace iron leaching (1.8\%) which may be resulted from both $\mathrm{Fe}_{2} \mathrm{O}_{3}$ core and $\mathrm{Fe}(\mathrm{III})$ salophencl. The second point was the deactivation and reusability of the catalyst. After each reaction, the catalyst could be easily separated and recovered from the reaction mixture by an external magnet and reused in subsequent reactions with just $3 \%$ loss of activity after 4 runs (Fig. 11B). These results confirmed the high reusability performance of title magnetically separable nanocatalyst in dye decolorization (Fig. 11B) as well as the structural integrity and durability of SMNP@SAET/ FeSal catalyst as evidenced by FT-IR spectra (Fig. 9B). These advantages highlight the merit of as-synthesized nanocomposites in comparison with previously reported catalysts, in terms of catalyst loading $(0.026 \mathrm{mM})$, reusability and stability of catalyst, efficiency and degradation rate of catalytic system and conditions used in the degradation of organic dyes. ${ }^{24,29,34,43}$

\section{Conclusion}

In conclusion, new thiolate- and Py-functionalized $\gamma-\mathrm{Fe}_{2} \mathrm{O}_{3}$ nanoparticles were prepared and used for coordinative anchoring of $\mathrm{Fe}(\mathrm{III})$ and $\mathrm{Mn}$ (III)salophen complexes. Four novel magnetically recoverable nanocomposites were characterized completely. Their catalytic efficiency in activation of $\mathrm{H}_{2} \mathrm{O}_{2}$ for degradation of organic dyes as water pollution through a heterogeneous advanced oxidation process (AOP) was evaluated. The decolorization efficiency was influenced by several parameters, such as temperature, the initial $\mathrm{pH}$, catalyst dosage, $\mathrm{H}_{2} \mathrm{O}_{2}$ and dyes concentration. Moreover, we found that the catalytic efficiency of $\mathrm{Fe}$ - and $\mathrm{Mn}$-salophen complexes were much more strongly affected by anchoring ligand environments. Particularly, $\pi$-donor thiolate anchoring ligand promoted markedly the efficiency and stability of Fe(III)salophen catalysts evidenced by experimental results and spectral data. A Fenton-like mechanism involving hydroxyl radicals was postulated according to fluorescence spectra of terephthalic acid as well as scavenging experiments. However, involvement of any secondary oxidant such as superoxide radical as well as high valent oxo iron should be taken into account. Rate constants for degradation of different dyes were larger than those reported for the related systems. The magnetically separable iron-based nanocatalysts proved to act heterogeneously with high reusability and excellent durability evidenced by FTIR spectra. Thus, the present work offers efficient, economical, environment-friendly and easy separable catalysts to treat environmental contaminants which is an enduring attention in recent years due to their great potential for environmental protection and remediation.

\section{Conflicts of interest}

There are no conflicts to declare.

\section{Acknowledgements}

Support of this work by research council of University of Birjand and the "Iran National Science Foundation" (grant no. 96005005) is highly appreciated. We would like to thank Prof. Dr Philipp Kurz and Sabine Zuelsdorf from Albert-Ludwigs University of Freiburg for friendly collaboration in some analysis.

\section{References}

1 F. H. AlHamedi, M. A. Rauf and S. S. Ashraf, Desalination, 2009, 239, 159-166.

2 Z. Qiu, Y. He, X. Liu and S. Yu, Chem. Eng. Process., 2005, 44, 1013-1017.

3 N. Daneshvar, D. Salari and A. R. Khataee, J. Photochem. Photobiol., A, 2003, 157, 111-116.

4 (a) J. An, L. Zhu, Y. Zhang and H. Tang, J. Environ. Sci., 2013, 25, 1213-1225; (b) N. M. Mahmoodi, Mater. Res. Bull., 2013, 48, 4255-4260; (c) G. Y. Mao, F. X. Bu, W. Wang, D. M. Jiang, Z. J. Zhao, Q. H. Zhang and J. S. Jiang, Desalin. Water Treat., 2016, 57, 9226-9236.

5 (a) E. Casbeer, V. K. Sharma and X. Z. Li, Sep. Purif. Technol., 2012, 87, 1-14; (b) S. Xu, D. Feng and W. Shangguan, J. Phys. 
Chem. C, 2009, 113, 2463-2467; (c) C. H. Chen, Y. H. Liang and W. D. Zhang, J. Alloys Compd., 2010, 501, 168-172; (d) J. Qiu, C. Wang and M. Gu, Mater. Sci. Eng., B, 2004, 112, 1-4.

6 (a) A. F. Ngomsik, A. Bee, M. Draye, G. Cote and V. Cabuil, $C$. R. Chim., 2005, 8, 963-970; (b) S. Thurm and S. Odenbach, J. Magn. Magn. Mater., 2002, 252, 247-249.

7 (a) C. Yang, J. Wu and Y. Hou, Chem. Commun., 2011, 47, 5130-5514; (b) S. Chen, Z. Xu, H. Dai and S. Zhang, J. Alloys Compd., 2010, 497, 221-227.

8 (a) Q. Zhang, X. Yang and J. Guan, ACS Appl. Nano Mater., 2019, 2, 4681-4697; (b) N. Panda, H. Sahoo and S. Mohapatra, J. Hazard. Mater., 2011, 1, 359-365; (c) A. Asfaram, M. Ghaedi, S. Hajati and A. Goudarzi, Ultrason. Sonochem., 2016, 32, 418-431; (d) L. Yue, K. Wang, J. Guo, J. Yang, X. Luo, J. Lian and L. Wang, J. Ind. Eng. Chem., 2014, 20, 725-731; (e) S. Sobhani and M. Honarmand, Applied Catalysis, A: General, 2013, 467, 456-462; $(f)$ E. Rafiee and S. Eavani, Green Chem., 2011, 13, 2116-2122.

9 (a) L. Wang, H. Qiu, C. Liang, P. Song, Y. Han, Y. Han, J. Gu, J. Kong, D. Pan and Z. Guo, Carbon, 2019, 141, 506-514; (b) J. Gu, L. Wang, C. Liang, Q. Zhuang and J. Kong, J. Alloys Compd., 2018, 745, 430-435; (c) Y. Huangfu, C. Liang, Y. Han, H. Qiu, P. Song, L. Wang, J. Kong and J. Gu, Compos. Sci. Technol., 2019, 169, 70-75; (d) C. Liang, P. Song, A. Ma, X. Shi, H. Gu, L. Wang, H. Qiu, J. Kong and J. Gu, Compos. Sci. Technol., 2019, 181, 107683; (e) L. M. Rossi, N. J. Costa, F. P. Silva and R. Wojcieszak, Green Chem., 2014, 16, 2906-2933; ( $f$ ) S. Palanisamy and Y. M. Wang, Dalton Trans., 2019, 48, 9490-9515; $(g)$ J. K. Xu, F. F. Zhang, J. J. Sun, J. Sheng, F. Wang and M. Sun, Molecules, 2014, 19, 21506-21528.

10 (a) P. Shi and N. Ye, Talanta, 2015, 143, 219-225; (b) M. Araghi and F. Bokaei, Polyhedron, 2013, 53, 15-19; (c) Y. Wang, P. Jiang, W. Zhang and J. Zheng, Appl. Surf. Sci., 2013, 270, 531-538; (d) F. Jia, L. Wu, J. Meng, M. Yang, H. Kong, T. Liu and H. Xu, J. Mater. Chem., 2009, 19, 89508957; (e) Z. B. Liu, J. G. Tian, Z. Guo, D. M. Ren, F. Du, J. Y. Zheng and Y. S. Chen, Adv. Mater., 2008, 20, 511-515.

11 T. L. Poulos, Chem. Rev., 2014, 114, 3919-3962.

12 S. Yoshioka, S. Takahashi, H. Hori, K. Ishimori and I. Morishima, Eur. J. Biochem., 2001, 268, 252-259.

13 K. U. Ingold, P. A. MacFaul and B. Meunier, ed. Meunier B, Biomimetic Oxidations Catalyzed by Transition Metal Complexes, World Scientific Publishing and Imperial College Press, London, 2000.

14 E. Brulé and Y. R. De Miguel, Org. Biomol. Chem., 2006, 4, 599-609.

15 (a) A. Rezaeifard, M. Jafarpour, P. Farshid and A. Naeimi, Eur. J. Inorg. Chem., 2012, 2012, 5515-5524; (b) A. Rezaeifard, M. Jafarpour, A. Naeimi and R. Haddad, Green Chem., 2012, 14, 3386-3394; (c) A. Rezaeifard, P. Farshid, M. Jafarpour and G. K. Moghaddam, RSC Adv., 2014, 4, 9189-9196.

16 A. Rezaeifard, M. Jafarpour, A. Farrokhi, S. Parvin and F. Feizpour, RSC Adv., 2016, 6, 64640-64650.
17 M. Jafarpour, A. Rezaeifard, V. Yasinzadeh and H. Kargar, RSC Adv., 2015, 5, 38460-38469.

18 K. Do Kim, S. S. Kim, Y. H. Choa and H. T. Kim, J. Ind. Eng. Chem., 2007, 13, 1137-1141.

19 J. H. Cai, J. W. Huang, P. Zhao, Y. J. Ye, H. C. Yu and L. N. Ji, J. Sol-Gel Sci. Technol., 2009, 50, 430-436.

20 C. Yuan, Z. Huang and J. Chen, Catal. Lett., 2011, 141, 14841490.

21 (a) L. Saikia, D. Srinivas and P. Ratnasamy, Microporous Mesoporous Mater., 2007, 104, 225-235; (b) P. Das, A. R. Silva, A. P. Carvalho, J. Pires and C. Freire, J. Mater. Sci., 2009, 44, 2865-2875.

22 E. Kadwa, M. D. Bala and H. B. Friedrich, Appl. Clay Sci., 2014, 95, 340-347.

23 (a) S. Sun and H. Zeng, J. Am. Chem. Soc., 2002, 124, 82048205; (b) B. Z. Tang, Y. Geng, J. W. Y. Lam, B. Li, X. Jing, X. Wang, F. Wang, A. B. Pakhomov and X. X Zhang, Chem. Mater., 1999, 11, 1581-1589.

24 N. Wang, L. Zhu, M. Wang, D. Wang and H. Tang, Ultrason. Sonochem., 2010, 17, 78-83.

25 A. Kreider-Mueller, P. J. Quinlivan, J. S. Owen and G. Parkin, Inorg. Chem., 2017, 56, 4643-4653.

26 (a) R. H. Holm, P. Kennepohl and E. I. Solomon, Chem. Rev., 1996, 96, 2239-2314; (b) W. N. Lipscomb and N. Sträter, Chem. Rev., 1996, 96, 2375-2434.

27 R. Jin, Nanoscale, 2010, 2, 343-362.

28 (a) N. Jaafarzadeh, A. Takdastan, S. Jorfi, F. Ghanbari, M. Ahmadi and G. Barzegar, J. Mol. Liq., 2018, 256, 462470; (b) X. Du, J. Wan, J. Jia, C. Pan, X. Hu, J. Fan and E. Liu, Mater. Des., 2017, 119, 113-123.

29 S. Gazi, A. Rajakumar and N. P. Singh, J. Hazard. Mater., 2010, 183, 894-901.

30 (a) C. P. Huang, Y. F. Huang, H. P. Cheng and Y. H. Huang, Catal. Commun., 2009, 10, 561-566; (b) J. H. Ramirez, F. M. Duarte, F. G. Martins, C. A. Costa and L. M. Madeira, Chem. Eng. J., 2009, 148, 394-404; (c) P. K. Malik, J. Phys. Chem. A, 2004, 108, 2675-2681; (d) D. Ni, J. Zhang, X. Wang, D. Qin, N. Li, W. Lu and W. Chen, Ind. Eng. Chem. Res., 2017, 56, 2899-2907.

31 (a) H. Li, J. Liao and T. Zeng, Catal. Commun., 2014, 46, 169173; (b) B. H. Hameed and T. W. Lee, J. Hazard. Mater., 2009, 164, 468-472; (c) S. P. Sun, C. J. Li, J. H. Sun, S. H. Shi, M. H. Fan and Q. Zhou, J. Hazard. Mater., 2009, 161, 10521057; (d) L. Narayanasamy and T. Murugesan, Environ. Prog. Sustainable Energy, 2014, 33, 482-489.

32 J. Bernadou and B. Meunier, Chem. Commun., 1998, 20, 2167-2173.

33 M. Arshadi, M. K. Abdolmaleki, F. Mousavinia, A. KhalafiNezhad, H. Firouzabadi and A. Gil, Chem. Eng. Res. Des., 2016, 112, 113-121.

34 (a) M. Wang, N. Wang, H. Tang, M. Cao, Y. She and L. Zhu, Catal. Sci. Technol., 2012, 2, 187-194; (b) F. Chen, S. Xie, X. Huang and X. Qiu, J. Hazard. Mater., 2017, 322, 152-162; (c) P. P. Gan and S. F. Y. Li, Chem. Eng. J., 2013, 229, 351-363.

35 P. Kennepohl, F. Neese, D. Schweitzer, H. L. Jackson, J. A. Kovacs and E. I. Solomon, Inorg. Chem., 2005, 44, 1826-1836. 
36 A. Rezaeifard, M. Jafarpour, H. Raissi, E. Ghiamati and A. Tootoonchi, Polyhedron, 2011, 30, 592-598.

37 (a) L. Saikia, D. Srinivas and P. Ratnasamy, Microporous Mesoporous Mater., 2007, 104, 225-235; (b) Z. Wang, W. D. Schenkeveld, S. M. Kraemer and D. E. Giammar, Environ. Sci. Technol., 2015, 49, 7236-7244; (c) K. N. T. Tseng, J. W. Kampf and N. K. Szymczak, ACS Catal., 2014, 5, 411-415.

38 I. A. Lobo, P. A. Robertson, L. Villani, D. J. Wilson and E. G. Robertson, J. Phys. Chem. A, 2018, 122, 7171-7180.

39 D. H. Gonzalez, X. M. Kuang, J. A. Scott, G. O. Rocha and S. E. Paulson, Anal. Lett., 2018, 51, 2488-2497.

40 D. Wang, J. Zou, H. Cai, Y. Huang, F. Li and Q. Cheng, Environ. Sci. Pollut. Res., 2019, 26, 1445-1454.

41 J. Zhuang, W. Dai, Q. Tian, Z. Li, L. Xie, J. Wang, P. Liu, X. Shi and D. Wang, Langmuir, 2010, 26, 9686-9694.

42 (a) J. Y. Li, P. X. Lei and J. C. Zhao, J. Environ. Sci., 2007, 19, 892-896; (b) Z. Chang and J. Zeng, RSC Adv., 2014, 4, 3897438977.
43 (a) Z. Han, X. Han, X. Zhao, J. Yu and H. Xu, J. Hazard. Mater., 2016, 320, 27-35; (b) Q. Song, M. Jia, W. Ma, Y. Fang and Y. Huang, Sci. China: Chem., 2013, 56, 1775-1782; (c) Q. Song, W. H. Ma, M. K. Jia, D. Johnson and Y. P. Huang, Applied Catalysis, A: General, 2015, 505, 70-76; (d) S. Yang, Y. Xu, Y. Sun, G. Zhang and D. Gao, CrystEngComm, 2012, 14, 7915-7921; (e) A. Umar, M. S. Akhtar, G. N. Dar and S. Baskoutas, Talanta, 2013, 116, 1060-1066; (f) N. Wang, L. Zhu, D. Wang, M. Wang, Z. Lin and H. Tang, Ultrason. Sonochem., 2010, 17, 526-533; (g) X. Tao, W. Ma, T. Zhang and J. Zhao, Chem. - Eur. J., 2002, 8, 1321-1326; (h) D. Lu, Y. Zhang, S. Lin, L. Wang and C. Wang, J. Alloys Compd., 2013, 579, 336-342; (i) Y. S. Lu, Z. Wang, Y. F. Xu, Q. Liu and G. R. Qian, Desalin. Water Treat., 2016, 57, 7898-7909; (j) W. J. Sun, J. Li, G. Mele, Z. Q. Zhang and F. X. Zhang, J. Mol. Catal. A: Chem., 2013, 366, 84-91. 